\title{
Common Fixed Points of Generalized Cyclic Meir-Keeler-Type Contractions in Partially Ordered Metric Spaces
}

\author{
Chiming Chen ${ }^{1}$ and Ing-Jer Lin ${ }^{2}$ \\ ${ }^{1}$ Department of Applied Mathematics, National Hsinchu University of Education, Taiwan \\ ${ }^{2}$ Department of Mathematics, National Kaohsiung Normal University, Taiwan
}

Correspondence should be addressed to Ing-Jer Lin; ijlin@nknucc.nknu.edu.tw

Received 19 June 2013; Accepted 2 August 2013

Academic Editor: E. Karapinar

Copyright (c) 2013 C. Chen and I.-J. Lin. This is an open access article distributed under the Creative Commons Attribution License, which permits unrestricted use, distribution, and reproduction in any medium, provided the original work is properly cited.

The purpose of this paper is to prove some common point theorems for the generalized cyclic Meir-Keeler-type $(\alpha, \varphi, A, B)$ contraction in partially ordered metric spaces. Our results generalize many recent common point theorems in the literature.

\section{Introduction and Preliminaries}

Throughout this paper, by $\mathbb{R}^{+}$, we denote the set of all nonnegative real numbers, while $\mathbb{N}$ is the set of all natural numbers. Let $(X, d)$ be a metric space, let $D$ be a subset of $X$, and let $f: D \rightarrow X$ be a map. We say that $f$ is contractive if there exists $\alpha \in[0,1)$ such that for all $x, y \in D$,

$$
d(f x, f y) \leq \alpha \cdot d(x, y) .
$$

The well-known Banach fixed point theorem asserts that if $D=X, f$ is contractive, and $(X, d)$ is complete, then $f$ has a unique fixed point in $X$. It is well known that the Banach contraction principle [1] is a very useful and classical tool in nonlinear analysis. Also, this principle has many generalizations. For instance, a mapping $f: X \rightarrow X$ is called a quasicontraction if there exists $k<1$ such that

$$
\begin{gathered}
d(f x, f y) \\
\leq k \cdot \max \{d(x, y), d(x, f x), d(y, f y), \\
d(x, f y), d(y, f x)\},
\end{gathered}
$$

for any $x, y \in X$. In 1974, Ćirić [2] introduced these maps and proved an existence and uniqueness fixed point theorem.

The following definitions and results will be needed in the sequel. Let $A$ and $B$ be two nonempty subsets of a metric space $(X, d)$. A mapping $f: A \cup B \rightarrow A \cup B$ is called a cyclic map if $f(A) \subseteq B$ and $f(B) \subseteq A$. In 2003, Kirk et al. [3, 4] proved the following fixed point theorem.

Theorem 1 (see $[3,4])$. Let $A$ and $B$ be two nonempty closed subsets of a complete metric space $(X, d)$, and suppose that $f$ : $A \cup B \rightarrow A \cup B$ satisfies

(i) $f(A) \subset B$ and $f(B) \subset A$,

(ii) $d(f x, f y) \leq k \cdot d(x, y)$ for all $x \in A, y \in B$, and $k \in(0,1)$.

Then $A \cap B$ is nonempty, and $f$ has a unique fixed point in $A \cap B$.

Recently, many authors proved some fixed point theorems for cyclic maps satisfying various contractive conditions (see, [5-20]).

Let $X$ be a nonempty set, and let $(X, \subseteq)$ be a partially ordered set endowed with a metric $d$. Then, the triple $(X, \sqsubseteq, d)$ is called a partially ordered metric space. Two elements $x, y \in$ $X$ are said to be comparable if either $x \sqsubseteq y$ or $y \sqsubseteq x$ holds. Altun et al. [21] introduced the notion of weakly increasing mappings and proved some existing theorems.

Definition 2 (see [21]). Let $(X, \sqsubseteq)$ be a partially ordered set and $f, g: X \rightarrow X$. Then $f, g$ are said to be weakly increasing if $f x \sqsubseteq g f x$ and $g x \sqsubseteq f g x$ for all $x \in X$.

And the following definition was introduced in [22]. 
Definition 3 (see [22]). Let $(X, \sqsubseteq)$ be a partially ordered set, let $A, B$ be closed subsets of $X$ with $X=A \cup B$, and let $f, g: X \rightarrow$ $X$. Then the pair $(f, g)$ is said to be $(A, B)$-weakly increasing if $f x \sqsubseteq g f x$ for all $x \in A$ and $g x \sqsubseteq f g x$ for all $x \in B$.

In this paper, we introduce the new notion of generalized cyclic Meir-Keeler-type $(\alpha, \psi, A, B)$-contraction. The purpose of this paper is to prove some common point theorems for the generalized cyclic Meir-Keeler-type $(\alpha, \psi, A, B)$-contraction in partially ordered metric spaces. Our results generalize many recent common point theorems in the literature.

\section{Main Results}

In the sequel, we denote by $\Psi$ the class of functions $\psi$ : $\mathbb{R}^{+5} \rightarrow \mathbb{R}^{+}$satisfying the following conditions:

$\left(\psi_{1}\right) \psi$ is an increasing, continuous function in each coordinate;

$\left(\psi_{2}\right)$ for all $t \in \mathbb{R}^{+}, \psi(t, t, t, 0,2 t) \leq t, \psi(t, t, t, 2 t, 0) \leq t$, $\psi(0,0, t, t, 0) \leq t$, and $\psi(t, 0,0, t, t) \leq t ;$

$\left(\psi_{2}\right) \psi\left(t_{1}, t_{2}, t_{3}, t_{4}, t_{5}\right)=0$ if and only if $t_{1}=t_{2}=t_{3}=t_{4}=$ $t_{5}=0$.

We start with the following definition.

Definition 4 (see [23]). Let $f: X \rightarrow X$ be a self-mapping of a set $X$ and $\alpha: X \times X \rightarrow \mathbb{R}^{+}$. Then $f$ is called $\alpha$-admissible if

$$
x, y \in X, \quad \alpha(x, y) \geq 1 \Longrightarrow \alpha(f x, f y) \geq 1 .
$$

Definition 5. Let $A, B$ be two nonempty subsets of a set $X$ with $X=A \cup B$, let $f: A \rightarrow B, g: B \rightarrow A$ with $f(A) \subset B$ and $g(B) \subset A$, and let $\alpha: X \times X \rightarrow \mathbb{R}^{+}$. Then the pair $(f, g)$ is called $\alpha$-admissible if the following conditions hold:

(1) $\alpha(f x, f x) \geq 1, \forall x \in A \Rightarrow \alpha(g f x, g f x) \geq 1$,

(2) $\alpha(g y, g y) \geq 1, \forall y \in B \Rightarrow \alpha(f g y, f g y) \geq 1$.

In 1969, Meir and Keeler [24] introduced the following notion of Meir-Keeler-type contraction in a metric space $(X, d)$.

Definition 6. Letting $(X, d)$ be a metric space, $f: X \rightarrow X$. Then $f$ is called a Meir-Keeler-type contraction whenever for each $\eta>0$, there exists $\gamma>0$ such that

$$
\eta \leq d(x, y)<\eta+\gamma \Longrightarrow d(f x, f y)<\eta .
$$

We now state the new notions of generalized cyclic MeirKeeler-type $(\psi, A, B)$-contractions and generalized MeirKeeler-type $(\alpha, \psi, A, B)$-contractions in partially ordered metric spaces as follows.

Definition 7 . Let $(X, \sqsubseteq, d)$ be a partially ordered metric space, let $A, B$ be two nonempty subsets of $X$ with $X=A \cup B$, and let $f: A \rightarrow B, g: B \rightarrow A$ with $f(A) \subset B$ and $g(B) \subset A$. Then the pair $(f, g)$ is called a generalized cyclic Meir-Keelertype $(\psi, A, B)$-contraction; if for any comparable elements $x$, $y \in X$ with $x \in A$ and $y \in B$, we have that for each $\eta>0$ there exists $\delta>0$ such that

$$
\begin{aligned}
\eta & \leq \psi(d(x, y), d(x, f x), d(y, g y), d(x, g y), d(y, f x)) \\
& <\eta+\delta \\
& \Longrightarrow d(f x, g y)<\eta
\end{aligned}
$$

where $\psi \in \Psi$.

Definition 8 . Let $(X, \sqsubseteq, d)$ be a partially ordered metric space, let $A, B$ be two nonempty subsets of $X$ with $X=A \cup B$, and let $f: A \rightarrow B, g: B \rightarrow A$ with $f(A) \subset B$ and $g(B) \subset A$, and $\alpha: X \times X \rightarrow \mathbb{R}^{+}$. Then $(f, g)$ is called a generalized cyclic Meir-Keeler-type $(\alpha, \psi, A, B)$-contraction if the following conditions hold:

(1) the pair $(f, g)$ is $\alpha$-admissible;

(2) for any comparable elements $x, y \in X$ with $x \in A$ and $y \in B$, we have that for each $\eta>0$ there exists $\delta>0$ such that

$$
\begin{aligned}
\eta & \leq \psi(d(x, y), d(x, f x), d(y, g y), d(x, g y), d(y, f x)) \\
& <\eta+\delta \\
& \Longrightarrow \alpha(f x, f x) \alpha(g y, g y) d(f x, g y)<\eta
\end{aligned}
$$

where $\psi \in \Psi$.

Remark 9. Note that if $f$ is a generalized cyclic Meir-Keelertype $(\alpha, \psi, A, B)$-contraction, then we have that for any comparable elements $x, y \in X$ with $x \in A$ and $y \in B$,

$$
\begin{aligned}
& \alpha(f x, f x) \alpha(g y, g y) d(f x, g y) \\
& \quad \leq \psi(d(x, y), d(x, f x), d(y, g y), d(x, g y), d(y, f x)) .
\end{aligned}
$$

Further, if

$$
\psi(d(x, y), d(x, f x), d(y, g y), d(x, g y), d(y, f x))=0,
$$

then $d(f x, g y)=0$.

On the other hand, if

$$
\psi(d(x, y), d(x, f x), d(y, g y), d(x, g y), d(y, f x))>0
$$

then

$$
\begin{aligned}
& \alpha(f x, f x) \alpha(g y, g y) d(f x, g y) \\
& \quad<\psi(d(x, y), d(x, f x), d(y, g y), d(x, g y), d(y, f x)) .
\end{aligned}
$$

We now state our first main result for the generalized cyclic Meir-Keeler-type $(\alpha, \psi, A, B)$-contraction as follows. 
Theorem 10. Let $(X, \sqsubseteq, d)$ be a partially ordered complete metric space, let $A, B$ be nonempty closed subsets of $X$ with $X=A \cup B$, let $\alpha: X \times X \rightarrow \mathbb{R}^{+}$, and let $f, g: X \rightarrow X$ be two mappings such that the pair $(f, g)$ is a generalized cyclic Meir-Keeler-type $(\alpha, \psi, A, B)$-contraction and $(A, B)$-weakly increasing. Suppose that the following conditions hold:

\section{(i) $f$ or $g$ is continuous;}

(ii) there exists $x_{0} \in A$ with $\alpha\left(f x_{0}, f x_{0}\right) \geq 1$;

(iii) if $\alpha\left(x_{n}, x_{n}\right) \geq 1$ for all $n \in \mathbb{N}$ and $\lim _{n \rightarrow \infty} x_{n}=v$, then $\alpha(f v, f v) \geq 1$ and $\alpha(g \nu, g v) \geq 1$.

\section{Then $f$ and $g$ have a common fixed point in $X$.}

Proof. By (ii), there exists $x_{0} \in X$ with $\alpha\left(f x_{0}, f x_{0}\right) \geq 1$. Since $f(A) \subset B$ and the pair $(f, g)$ is $\alpha$-admissible, there exists $x_{1} \in$ $B$ such that

$$
x_{1}=f x_{0}, \quad \alpha\left(g x_{1}, g x_{1}\right)=\alpha\left(g f x_{0}, g f x_{0}\right) \geq 1 .
$$

Since $g(B) \subset A$ and the pair $(f, g)$ is $\alpha$-admissible, there exists $x_{2} \in A$ such that

$$
x_{2}=g x_{1}, \quad \alpha\left(f x_{2}, f x_{2}\right)=\alpha\left(f g x_{1}, f g x_{1}\right) \geq 1 .
$$

Continuing this process, we construct the sequence $\left\{x_{n}\right\}$ in $X$ such that

$$
\begin{array}{r}
x_{2 n+1}=f x_{2 n}, \quad x_{2 n+2}=g x_{2 n+1}, \\
x_{2 n} \in A, x_{2 n+1} \in B,
\end{array}
$$

and for all $n \in \mathbb{N} \cup\{0\}$,

$$
\begin{gathered}
\alpha\left(x_{2 n+1}, x_{2 n+1}\right)=\alpha\left(f x_{2 n}, f x_{2 n}\right) \geq 1, \\
\alpha\left(x_{2 n+2}, x_{2 n+2}\right)=\alpha\left(g x_{2 n+1}, g x_{2 n+1}\right) \geq 1 .
\end{gathered}
$$

Since the pair $(f, g)$ is $(A, B)$-weakly increasing, we have that

$$
x_{1}=f x_{0} \sqsubseteq g f x_{0}=g x_{1}=x_{2} \sqsubseteq f g x_{1}=f x_{2}=x_{3} \sqsubseteq \cdots,
$$

and so we conclude that for all $n \in \mathbb{N} \cup\{0\}$,

$$
g f x_{2 n}=g x_{2 n+1}=x_{2 n+2} \sqsubseteq f g x_{2 n+1}=f x_{2 n+2}=x_{2 n+3} .
$$

Step 1. We will show that $\left\{x_{n}\right\}$ is a Cauchy sequence in $(X, \sqsubseteq, d)$.
Case 1. Suppose that $x_{2 n}=x_{2 n+1}$ for some $n \in \mathbb{N}$ in the inequality (16). Since $x_{2 n}$ and $x_{2 n+1}$ are comparable in $X$ with $x_{2 n} \in A$ and $x_{2 n+1} \in B$, by the Remark 9, we have

$$
\begin{aligned}
& d\left(x_{2 n+1}, x_{2 n+2}\right) \\
& =d\left(f x_{2 n}, g x_{2 n+1}\right) \\
& \leq \alpha\left(f x_{2 n}, f x_{2 n}\right) \alpha\left(g x_{2 n+1}, g x_{2 n+1}\right) d\left(f x_{2 n}, g x_{2 n+1}\right) \\
& \leq \psi\left(d\left(x_{2 n}, x_{2 n+1}\right), d\left(x_{2 n}, f x_{2 n}\right), d\left(x_{2 n+1}, g x_{2 n+1}\right),\right. \\
& \left.\quad d\left(x_{2 n}, g x_{2 n+1}\right), d\left(x_{2 n+1}, f x_{2 n}\right)\right) \\
& =\psi\left(d\left(x_{2 n}, x_{2 n+1}\right), d\left(x_{2 n}, x_{2 n+1}\right), d\left(x_{2 n+1}, x_{2 n+2}\right),\right. \\
& \left.\quad d\left(x_{2 n}, x_{2 n+2}\right), d\left(x_{2 n+1}, x_{2 n+1}\right)\right) \\
& \leq \psi\left(0,0, d\left(x_{2 n+1}, x_{2 n+2}\right), d\left(x_{2 n+1}, x_{2 n+2}\right), 0\right) .
\end{aligned}
$$

If $d\left(x_{2 n+1}, x_{2 n+2}\right)>0$, then $\psi\left(0,0, d\left(x_{2 n+1}, x_{2 n+2}\right), d\left(x_{2 n+1}\right.\right.$, $\left.\left.x_{2 n+2}\right), 0\right)>0$. By Remark 9, we get a contradiction. So we conclude that $d\left(x_{2 n+1}, x_{2 n+2}\right)=0$; that is, $x_{2 n+1}=x_{2 n+2}$. Similarly, we may show that $x_{2 n+2}=x_{2 n+3}$. Hence $\left\{x_{n}\right\}$ is a constant sequence, and so $\left\{x_{n}\right\}$ is a Cauchy sequence in $(X, \sqsubseteq, d)$.

Case 2. Suppose that $x_{2 n} \neq x_{2 n+1}$ for all $n \in \mathbb{N}$ in the inequality (16).

Substep 1. We show that the sequence $\left\{d\left(x_{n}, x_{n+1}\right): n \in \mathbb{N} \cup\right.$ $\{0\}\}$ is decreasing.

Subcase 1. If $n$ is even, then we let $n=2 m$ for some $m \in \mathbb{N}$. Since $x_{2 m} \in A, x_{2 m+1} \in B$, and $x_{2 m}, x_{2 m+1}$ are comparable in $X$, we have

$$
\begin{aligned}
& d\left(x_{n+1}, x_{n+2}\right) \\
& =d\left(x_{2 m+1}, x_{2 m+2}\right)=d\left(f x_{2 m}, g x_{2 m+1}\right) \\
& \leq \alpha\left(f x_{2 m}, f x_{2 m}\right) \alpha\left(g x_{2 m+1}, g x_{2 m+1}\right) d\left(f x_{2 m}, g x_{2 m+1}\right) \\
& <\psi\left(d\left(x_{2 m}, x_{2 m+1}\right), d\left(x_{2 m}, f x_{2 m}\right), d\left(x_{2 m+1}, g x_{2 m+1}\right),\right. \\
& \left.\quad d\left(x_{2 m}, g x_{2 m+1}\right), d\left(x_{2 m+1}, f x_{2 m}\right)\right) \\
& =\psi\left(d\left(x_{2 m}, x_{2 m+1}\right), d\left(x_{2 m}, x_{2 m+1}\right), d\left(x_{2 m+1}, x_{2 m+2}\right),\right. \\
& \left.\quad d\left(x_{2 m}, x_{2 m+2}\right), d\left(x_{2 m+1}, x_{2 m+1}\right)\right) \\
& \leq \psi\left(d\left(x_{2 m}, x_{2 m+1}\right), d\left(x_{2 m}, x_{2 m+1}\right), d\left(x_{2 m+1}, x_{2 m+2}\right),\right. \\
& \left.\quad d\left(x_{2 m}, x_{2 m+1}\right)+d\left(x_{2 m+1}, x_{2 m+2}\right), 0\right) \\
& =\psi\left(d\left(x_{n}, x_{n+1}\right), d\left(x_{n}, x_{n+1}\right), d\left(x_{n+1}, x_{n+2}\right),\right. \\
& \left.\quad d\left(x_{n}, x_{n+1}\right)+d\left(x_{n+1}, x_{n+2}\right), 0\right) .
\end{aligned}
$$


If $d\left(x_{2 m}, x_{2 m+1}\right)<d\left(x_{2 m+1}, x_{2 m+2}\right)$, then the above inequality becomes

$$
\begin{aligned}
& d\left(x_{2 m+1}, x_{2 m+2}\right) \\
& <\psi\left(d\left(x_{2 m+1}, x_{2 m+2}\right), d\left(x_{2 m+1}, x_{2 m+2}\right),\right. \\
& \left.\quad d\left(x_{2 m+1}, x_{2 m+2}\right), 2 d\left(x_{2 m+1}, x_{2 m+2}\right), 0\right) \\
& \leq d\left(x_{2 m+1}, x_{2 m+2}\right),
\end{aligned}
$$

which is a contradiction. So we have that

$$
d\left(x_{2 m+1}, x_{2 m+2}\right) \leq d\left(x_{2 m}, x_{2 m+1}\right) .
$$

Subcase 2. If $n$ is odd, then we let $n=2 m+1$ for some $m \in \mathbb{N}$. Since $x_{2 m+2} \in A, x_{2 m+3} \in B$ and $x_{2 m+2}, x_{2 m+3}$ are comparable in $X$, we have

$$
\begin{aligned}
& d\left(x_{n+2}, x_{n+1}\right) \\
&= d\left(x_{2 m+3}, x_{2 m+2}\right)=d\left(f x_{2 m+2}, g x_{2 m+1}\right) \\
& \leq \alpha\left(f x_{2 m+2}, f x_{2 m+2}\right) \alpha\left(g x_{2 m+1}, g x_{2 m+1}\right) \\
& \times d\left(f x_{2 m+2}, g x_{2 m+1}\right) \\
&< \psi\left(d\left(x_{2 m+2}, x_{2 m+1}\right), d\left(x_{2 m+2}, f x_{2 m+2}\right),\right. \\
& d\left(x_{2 m+1}, g x_{2 m+1}\right), d\left(x_{2 m+2}, g x_{2 m+1}\right), \\
&\left.\quad d\left(x_{2 m+1}, f x_{2 m+2}\right)\right) \\
&= \psi\left(d\left(x_{2 m+2}, x_{2 m+1}\right), d\left(x_{2 m+2}, x_{2 m+3}\right), d\left(x_{2 m+1}, x_{2 m+2}\right),\right. \\
&\left.\quad d\left(x_{2 m+2}, x_{2 m+2}\right), d\left(x_{2 m+1}, x_{2 m+3}\right)\right) \\
& \leq\left(d\left(x_{2 m+2}, x_{2 m+1}\right), d\left(x_{2 m+2}, x_{2 m+3}\right), d\left(x_{2 m+1}, x_{2 m+2}\right),\right. \\
&\left.\quad 0, d\left(x_{2 m+1}, x_{2 m+2}\right)+d\left(x_{2 m+2}, x_{2 m+3}\right)\right) \\
&=\psi\left(d\left(x_{n+1}, x_{n}\right), d\left(x_{n+1}, x_{n+2}\right), d\left(x_{n}, x_{n+1}\right),\right. \\
&\left.\quad 0, d\left(x_{n}, x_{n+1}\right)+d\left(x_{n+1}, x_{n+2}\right)\right) .
\end{aligned}
$$

If $d\left(x_{2 m+1}, x_{2 m+2}\right)<d\left(x_{2 m+2}, x_{2 m+3}\right)$, then the above inequality becomes

$$
\begin{aligned}
& d\left(x_{2 m+2}, x_{2 m+3}\right) \\
& <\psi\left(d\left(x_{2 m+2}, x_{2 m+3}\right), d\left(x_{2 m+2}, x_{2 m+3}\right),\right. \\
& \left.\quad d\left(x_{2 m+3}, x_{2 m+3}\right), 0,2 d\left(x_{2 m+2}, x_{2 m+3}\right)\right) \\
& \leq d\left(x_{2 m+2}, x_{2 m+3}\right),
\end{aligned}
$$

which is a contradiction. So we have that

$$
d\left(x_{2 m+2}, x_{2 m+3}\right)<d\left(x_{2 m+1}, x_{2 m+2}\right) .
$$

From (20) and (23), we conclude that

$$
d\left(x_{+1}, x_{n+2}\right)<d\left(x_{n+1}, x_{n+1}\right) .
$$

From the above argument, we have that the sequence $\left\{d\left(x_{n}\right.\right.$, $\left.\left.x_{n+1}\right): n \in \mathbb{N} \cup\{0\}\right\}$ is decreasing, and it must converge to some $\eta \geq 0$; that is,

$$
\lim _{n \rightarrow \infty} d\left(x_{n}, x_{n+1}\right)=\eta
$$

Substep 2. We next claim that

$$
\lim _{n \rightarrow \infty} d\left(x_{n}, f x_{n+1}\right)=0 .
$$

Notice that $\eta=\inf \left\{d\left(f x_{n}, f x_{n+1}\right): n \in \mathbb{N} \cup\{0\}\right\}$. We claim that $\eta=0$. Suppose, to the contrary, that $\eta>0$.

If $n$ is even, by the argument of Subcase 1 and the inequality (25), we have

$$
\begin{gathered}
\lim _{n \rightarrow \infty} \psi\left(d\left(x_{n}, x_{n+1}\right), d\left(x_{n}, x_{n+1}\right), d\left(x_{n+1}, x_{n+2}\right),\right. \\
\left.d\left(x_{n}, x_{n+1}\right)+d\left(x_{n+1}, x_{n+2}\right), 0\right)=\eta .
\end{gathered}
$$

Since $(f, g)$ is a generalized cyclic Meir-Keeler-type ( $\alpha, \psi$, $A, B)$-contraction, corresponding to $\eta$ use and taking into account the above (27), there exist $\delta>0$ and a natural number $k$ such that

$$
\begin{gathered}
\eta \leq \psi\left(d\left(x_{k}, x_{k+1}\right), d\left(x_{k}, x_{k+1}\right), d\left(x_{k+1}, x_{k+2}\right), d\left(x_{k}, x_{k+1}\right)\right. \\
\left.+d\left(x_{k+1}, x_{k+2}\right), 0\right)<\eta+\delta \\
\Longrightarrow \alpha\left(f x_{k}, f x_{k}\right) \alpha\left(g x_{k+1}, g x_{k+1}\right) d\left(f x_{k}, g x_{k+1}\right)<\eta,
\end{gathered}
$$

which implies

$$
\begin{aligned}
& d\left(f x_{k}, g x_{k+1}\right) \\
& \quad \leq \alpha\left(f x_{k}, f x_{k}\right) \alpha\left(g x_{k+1}, g x_{k+1}\right) d\left(f x_{k}, g x_{k+1}\right)<\eta .
\end{aligned}
$$

So we get a contradiction, since $\eta=\inf \left\{d\left(x_{n}, x_{n+1}\right): n \in\right.$ $\mathbb{N} \cup\{0\}$. Thus we have that

$$
\lim _{n \rightarrow \infty} d\left(x_{n}, f x_{n+1}\right)=0 .
$$

If $n$ is odd, by the argument of Subcase 2 and the inequality (25), we have

$$
\begin{gathered}
\lim _{n \rightarrow \infty} \psi\left(d\left(x_{n+1}, x_{n}\right), d\left(x_{n+1}, x_{n+2}\right), d\left(x_{n}, x_{n+1}\right),\right. \\
\left.0, d\left(x_{n}, x_{n+1}\right)+d\left(x_{n+1}, x_{n+2}\right)\right)=\eta .
\end{gathered}
$$

Similarly, we can prove that

$$
\lim _{n \rightarrow \infty} d\left(x_{n}, f x_{n+1}\right)=0 .
$$

Substep 3. We show that $\left\{x_{n}\right\}$ is a Cauchy sequence in $(X$, $d)$. It is sufficient to show that $\left\{x_{2 n}\right\}$ is a Cauchy sequence in $(X, \sqsubseteq, d)$.

Suppose, to the contrary, that $\left\{x_{2 n}\right\}$ is not a Cauchy sequence in $(X, \sqsubseteq, d)$. Then there exist $\epsilon>0$ and two 
subsequences $\left\{x_{2 m(k)}\right\}$ and $\left\{x_{2 n(k)}\right\}$ of $\left\{x_{2 n}\right\}$ such that $n(k)$ is the smallest integer for which $n(k)>m(k)>k$,

$$
d\left(x_{2 m(k)}, x_{2 n(k)}\right) \geq \epsilon, \quad d\left(x_{2 m(k)}, x_{2 n(k)-2}\right)<\epsilon,
$$

and we get

$$
\begin{aligned}
\epsilon \leq & d\left(x_{2 m(k)}, x_{2 n(k)}\right) \\
\leq & d\left(x_{2 m(k)}, x_{2 n(k)-2}\right)+d\left(x_{2 n(k)-2}, x_{2 n(k)-1}\right) \\
& +d\left(x_{2 n(k)-1}, x_{2 n(k)}\right) \\
& <\epsilon+d\left(x_{2 n(k)-2}, x_{2 n(k)-1}\right)+d\left(x_{2 n(k)-1}, x_{2 n(k)}\right) .
\end{aligned}
$$

Letting $k \rightarrow \infty$ in the above inequality, we get

$$
\lim _{n \rightarrow \infty} d\left(x_{2 m(k)}, x_{2 n(k)}\right)=\epsilon
$$

On the other hand, we also obtain that

$$
\begin{aligned}
\epsilon \leq & d\left(x_{2 m(k)}, x_{2 n(k)}\right) \\
\leq & d\left(x_{2 m(k)}, x_{2 n(k)-1}\right)+d\left(x_{2 n(k)-1}, x_{2 n(k)}\right) \\
\leq & d\left(x_{2 m(k)+1}, x_{2 n(k)-1}\right)+d\left(x_{2 m(k)}, x_{2 m(k)+1}\right) \\
& +d\left(x_{2 n(k)-1}, x_{2 n(k)}\right) \\
\leq & d\left(x_{2 m(k)}, x_{2 n(k)-1}\right)+2 d\left(x_{2 m(k)}, x_{2 m(k)+1}\right) \\
& +d\left(x_{2 n(k)-1}, x_{2 n(k)}\right) \\
\leq & d\left(x_{2 m(k)}, x_{2 n(k)}\right)+2 d\left(x_{2 m(k)}, x_{2 m(k)+1}\right) \\
& +2 d\left(x_{2 n(k)-1}, x_{2 n(k)}\right) .
\end{aligned}
$$

Letting $k \rightarrow \infty$ in the above inequality, we get

$$
\begin{aligned}
& \lim _{n \rightarrow \infty} d\left(x_{2 m(k)}, x_{2 n(k)}\right) \\
& =\lim _{n \rightarrow \infty} d\left(x_{2 m(k)}, x_{2 n(k)-1}\right) \\
& =\lim _{n \rightarrow \infty} d\left(x_{2 m(k)+1}, x_{2 n(k)-1}\right) \\
& =\epsilon .
\end{aligned}
$$

Since

$$
\begin{aligned}
& d\left(x_{2 m(k)+1}, x_{2 n(k)-1}\right) \\
& \quad \leq d\left(x_{2 m(k)+1}, x_{2 n(k)}\right)+d\left(x_{2 n(k)}, x_{2 n(k)-1}\right) \\
& \quad \leq d\left(x_{2 m(k)+1}, x_{2 n(k)-1}\right)+2 d\left(x_{2 n(k)}, x_{2 n(k)-1}\right),
\end{aligned}
$$

letting $k \rightarrow \infty$ in the above inequality, we have

$$
\lim _{n \rightarrow \infty} d\left(x_{2 m(k)+1}, x_{2 n(k)}\right)=\epsilon .
$$

Since $x_{2 m(k)} \in A, x_{2 n(k)-1} \in B$, and $x_{2 m(k)}, x_{2 n(k)-1}$ are comparable in $X$, we have

$$
\begin{aligned}
& d\left(x_{2 m(k)+1}, x_{2 n(k)}\right) \\
& =d\left(f x_{2 m(k)}, g x_{2 n(k)-1}\right) \\
& \leq \alpha\left(f x_{2 m(k)}, f x_{2 m(k)}\right) \alpha\left(g x_{2 n(k)-1}, g x_{2 n(k)-1}\right) \\
& \times d\left(f x_{2 m(k)}, g x_{2 n(k)-1}\right) \\
& <\psi\left(d\left(x_{2 m(k)}, x_{2 n(k)-1}\right), d\left(x_{2 m(k)}, f x_{2 m(k)}\right),\right. \\
& d\left(x_{2 n(k)-1}, g x_{2 n(k)-1}\right), d\left(x_{2 m(k)}, g x_{2 n(k)-1}\right), \\
& \left.d\left(x_{2 n(k)-1}, f x_{2 m(k)}\right)\right) \\
& =\psi\left(d\left(x_{2 m(k)}, x_{2 n(k)-1}\right), d\left(x_{2 m(k)}, x_{2 m(k)+1}\right)\right. \text {, } \\
& d\left(x_{2 n(k)-1}, x_{2 n(k)}\right), d\left(x_{2 m(k)}, x_{2 n(k)}\right) \text {, } \\
& \left.d\left(x_{2 n(k)-1}, x_{2 m(k)+1}\right)\right) \text {. }
\end{aligned}
$$

Letting $k \rightarrow \infty$ in the above inequality and using (37) and (39), we get

$$
\epsilon=\lim _{n \rightarrow \infty} d\left(x_{2 m(k)+1}, x_{2 n(k)}\right)<\psi(\epsilon, 0,0, \epsilon, \epsilon) \leq \epsilon,
$$

which implies a contradiction. So we get that $\left\{x_{n}\right\}$ is a Cauchy sequence in $(X, \sqsubseteq, d)$.

Step 2. Finally, we prove the existence of common fixed point of $f$ and $g$.

Since $(X, \sqsubseteq, d)$ is complete and $\left\{x_{n}\right\}$ is a Cauchy sequence in $(X, \sqsubseteq, d)$, there exists $v \in X$ such that

$$
\lim _{n \rightarrow \infty} x_{n}=\lim _{n \rightarrow \infty} x_{2 n}=\lim _{n \rightarrow \infty} x_{2 n-1}=\nu .
$$

From (42) and since $\alpha\left(x_{n}, x_{n}\right) \geq 1$ for all $n \in \mathbb{N}$, we have $\alpha(f v, f v) \geq 1$ and $\alpha(g \nu, g v) \geq 1$.

Since $\left\{x_{2 n}\right\}$ is a sequence in $A$ and $A$ is closed, by (42), we have that $v \in A$. Similarly, since $\left\{x_{2 n+1}\right\}$ is a sequence in $B$ and $B$ is closed, by (42), we have that $\nu \in B$. We now claim that $\nu$ is a common fixed point of $f$ and $g$. Without loss of generality, we assume that $f$ is continuous, and by (42), we have

$$
x_{2 n+1}=f x_{2 n} \longrightarrow \nu, \quad \text { as } n \rightarrow \infty .
$$

By the uniqueness of the limit, we have that $v=f \nu$.

Since $v \sqsubseteq v$ with $v \in A$ and $\nu \in B$, we have

$$
\begin{aligned}
d(\nu, g v)= & d(f v, g v) \\
\leq & \alpha(f v, f v) \alpha(g v, g v) d(f v, g v) \\
< & \psi(d(v, v), d(v, f v), d(v, g v), \\
& d(v, g v), d(v, f v)) \\
= & \psi(0,0, d(v, g v), d(v, g v), 0) \\
\leq & d(v, g v) .
\end{aligned}
$$

This implies that $v=g v$. So we complete the proof. 
Applying Theorem 10 and if we let $\alpha(x, y)=1$, then we immediately get the following theorem.

Theorem 11. Let $(X, \sqsubseteq, d)$ be a partially ordered complete metric space, let $A, B$ be nonempty closed subsets of $X$ with $X=A \cup B$, and let $f, g: X \rightarrow X$ be two mappings such that the pair $(f, g)$ is a generalized cyclic Meir-Keeler-type $(\psi, A, B)$-contraction and $(A, B)$-weakly increasing. If $f$ or $g$ is continuous, then $f$ and $g$ have a common fixed point in $X$.

We next state our second main result for the generalized cyclic Meir-Keeler-type $(\alpha, \psi, A, B)$-contraction as follows.

Theorem 12. Let $(X, \sqsubseteq, d)$ be a partially ordered complete metric space, let $A, B$ be nonempty closed subsets of $X$ with $X=A \cup B$, let $\alpha: X \times X \rightarrow \mathbb{R}^{+}$, and let $f, g: X \rightarrow X$ be two mappings such that the pair $(f, g)$ is a generalized cyclic Meir-Keeler-type $(\alpha, \psi, A, B)$-contraction and $(A, B)$-weakly increasing. Suppose that the following conditions hold:

(i) if $\left\{x_{n}\right\}$ is a nondecreasing sequence in $X$ and $\lim _{n \rightarrow \infty} x_{n}=v$, then $x_{n} \sqsubseteq v$;

(ii) there exists $x_{0} \in A$ with $\alpha\left(f x_{0}, f x_{0}\right) \geq 1$;

(iii) if $\alpha\left(x_{n}, x_{n}\right) \geq 1$ for all $n \in \mathbb{N}$ and $\lim _{n \rightarrow \infty} x_{n}=v$, then $\alpha(f \nu, f \nu) \geq 1$ and $\alpha(g \nu, g \nu) \geq 1$.

Then $f$ and $g$ have a common fixed point in $X$.

Proof. From the same proof's process of Theorem 10, we can construct a nondecreasing sequence $\left\{x_{n}\right\}$ in $X$ with $x_{2 n} \in A$, $x_{2 n+1} \in B$, and $x_{n} \rightarrow \nu$ for some $\nu \in X$. Since $x_{n} \rightarrow \nu$ and $A, B$ are nonempty closed subsets of $X$, we have $x_{2 n} \rightarrow \nu$, $x_{2 n+1} \rightarrow v$, and $\nu \in A \cap B$. By the condition (i), we get $x_{n} \sqsubseteq v$ for all $n \in \mathbb{N}$.

Since $x_{2 n} \in A$ and $v \in B$, we have

$$
\begin{gathered}
d\left(x_{2 n+1}, g v\right) \\
=d\left(f x_{2 n}, g v\right) \\
\leq \alpha\left(f x_{2 n}, f x_{2 n}\right) \alpha(g v, g v) d\left(f x_{2 n}, g v\right) \\
<\psi\left(d\left(x_{2 n}, v\right), d\left(x_{2 n}, f x_{2 n}\right), d(v, g v),\right. \\
\left.\quad d\left(x_{2 n}, g v\right), d\left(v, f x_{2 n}\right)\right) \\
=\psi\left(d\left(x_{2 n}, v\right), d\left(x_{2 n}, x_{2 n+1}\right), d(v, g v),\right. \\
\left.\quad d\left(x_{2 n}, g v\right), d\left(v, x_{2 n+1}\right)\right) .
\end{gathered}
$$

Letting $n \rightarrow \infty$ in the above inequality, we get

$$
d(\nu, g v)<\psi(0,0, d(\nu, g v), d(\nu, g v), 0) \leq d(\nu, g v) \text {. }
$$

This implies that $d(v, g v)=0$; that is, $v=g v$. Similarly, we may show that $\nu=f \nu$. So $v$ is a common fixed point of $f$ and g.

Applying Theorem 12, it is easy to get the following theorem.
Theorem 13. Let $(X, \sqsubseteq, d)$ be a partially ordered complete metric space, let $A, B$ be nonempty closed subsets of $X$ with $X=A \cup B$, and let $f, g: X \rightarrow X$ be two mappings such that the pair $(f, g)$ is a generalized cyclic Meir-Keeler-type $(\psi, A, B)$-contraction and $(A, B)$-weakly increasing. Suppose that the following condition holds:

$$
\begin{aligned}
& \text { if }\left\{x_{n}\right\} \text { is a nondecreasing sequence in } X \text { and } \\
& \lim _{n \rightarrow \infty} x_{n}=v \text {, then } x_{n} \sqsubseteq v \text {. }
\end{aligned}
$$

Then $f$ and $g$ have a common fixed point in $X$.

\section{References}

[1] S. Banach, "Sur les operations dans les ensembles abstraits et leur application aux equations integerales," Fundamenta Mathematicae, vol. 3, pp. 133-181, 1922.

[2] Lj. B. Ćirić, "A generalization of Banach's contraction principle," Proceedings of the American Mathematical Society, vol. 45, pp. 133-181, 1974.

[3] W. A. Kirk, P. S. Srinivasan, and P. Veeramani, "Fixed points for mappings satisfying cyclical contractive conditions," Fixed Point Theory, vol. 4, no. 1, pp. 79-89, 2003.

[4] C. M. Chen, "Fixed point theorems for cyclic Meir-Keeler type mappings in complete metric spaces," Fixed Point Theory and Applications, vol. 2012, article 41, 2012.

[5] C.-M. Chen and C.-H. Chen, "Best proximity point theorems for some new cyclic mappings," Journal of Applied Mathematics, vol. 2012, Article ID 643729, 14 pages, 2012.

[6] C. Chen and C. Lin, "Best periodic proximity points for cyclic weaker Meir-Keeler contractions," Journal of Applied Mathematics, vol. 2012, Article ID 782389, 7 pages, 2012.

[7] C.-M. Chen, "Fixed point theory for the cyclic weaker MeirKeeler function in complete metric spaces," Fixed Point Theory and Applications, vol. 2012, article 17, 2012.

[8] S. Karpagam and S. Agrawal, "Best proximity point theorems for cyclic orbital Meir-Keeler contraction maps," Nonlinear Analysis. Theory, Methods \& Applications, vol. 74, no. 4, pp. 1040-1046, 2011.

[9] S. Karpagam and S. Agrawal, "Existence of best proximity points of p-contractions," Fixed Point Theory, vol. 13, no. 1, pp. 99-105, 2012.

[10] E. Karapinar, "Fixed point theory for cyclic weak $\phi$-contraction," Applied Mathematics Letters, vol. 24, no. 6, pp. 822825,2011

[11] E. Karapınar, "Best proximity points of cyclic mappings," Applied Mathematics Letters, vol. 25, no. 11, pp. 1761-1766, 2012.

[12] E. Karapınar, I. M. Erhan, and A. Y. Ulus, "Fixed point theorem for cyclic maps on partial metric spaces," Applied Mathematics \& Information Sciences, vol. 6, no. 2, pp. 239-244, 2012.

[13] E. Karapinar and K. Sadarangani, "Fixed point theory for cyclic $(\varphi-\phi)$-contractions," Fixed Point Theory and Applications, vol. 2011, article 69, 2011.

[14] E. Karapınar and I. M. Erhan, "Cyclic contractions and fixed point theorems," Filomat, vol. 4, pp. 777-782, 2012.

[15] E. Karapınar, G. Petrusel, and K. Tas, "Best proximity point theorems for KTtypes cyclic orbital contraction mappings," Fixed Point Theory. In press.

[16] M. Jleli, E. Karapınar, and B. Samet, "Fixed point results for almost generalized cyclic $(\varphi, \phi)$-weak contractive type mappings with applications," Abstract and Applied Analysis, vol. 2013, Article ID 917831, 17 pages, 2012. 
[17] E. Karapınar, S. Romaguera, and K. Taş, "Fixed points for cyclic orbital generalized contractions on complete metric spaces," Central European Journal of Mathematics, vol. 11, no. 3, pp. 552560, 2013.

[18] W. A. Kirk, P. S. Srinivasan, and P. Veeramani, "Fixed points for mappings satisfying cyclical contractive conditions," Fixed Point Theory, vol. 4, no. 1, pp. 79-89, 2003.

[19] M. Păcurar and I. A. Rus, "Fixed point theory for cyclic $\phi$ contractions," Nonlinear Analysis. Theory, Methods \& Applications, vol. 72, no. 3-4, pp. 1181-1187, 2010.

[20] M. Derafshpour, S. Rezapour, and N. Shahzad, "Best proximity points of cyclic $\phi$-contractions in ordered metric spaces," Topological Methods in Nonlinear Analysis, vol. 37, no. 1, pp. 193202, 2011.

[21] I. Altun, B. Damjanović, and D. Djorić, "Fixed point and common fixed point theorems on ordered cone metric spaces," Applied Mathematics Letters, vol. 23, no. 3, pp. 310-316, 2010.

[22] W. Shatanawi and M. Postslanche, "Common fixed point results for mappings under nonlinear contraction of cyclic form in ordered cone metric spaces," Fixed Point Theory and Applications, vol. 2013, article 60, 2013.

[23] B. Samet, C. Vetro, and P. Vetro, "Fixed point theorems for $\alpha-\varphi$-contractive type mappings," Nonlinear Analysis. Theory, Methods \& Applications, vol. 75, no. 4, pp. 2154-2165, 2012.

[24] A. Meir and E. Keeler, "A theorem on contraction mappings," Journal of Mathematical Analysis and Applications, vol. 28, pp. 326-329, 1969. 


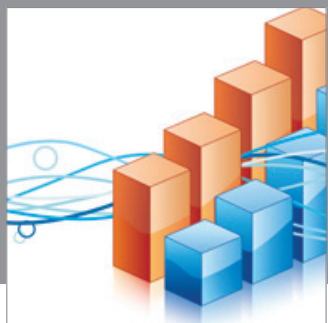

Advances in

Operations Research

mansans

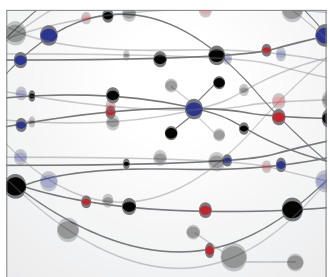

The Scientific World Journal
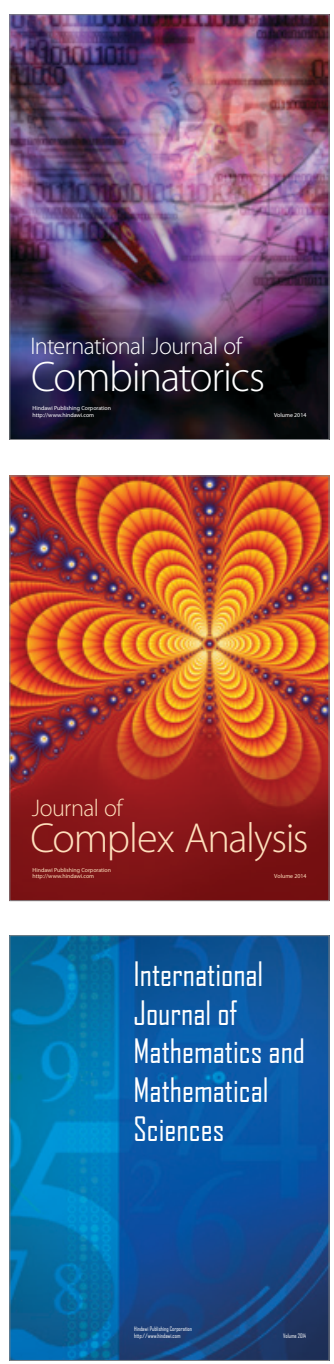
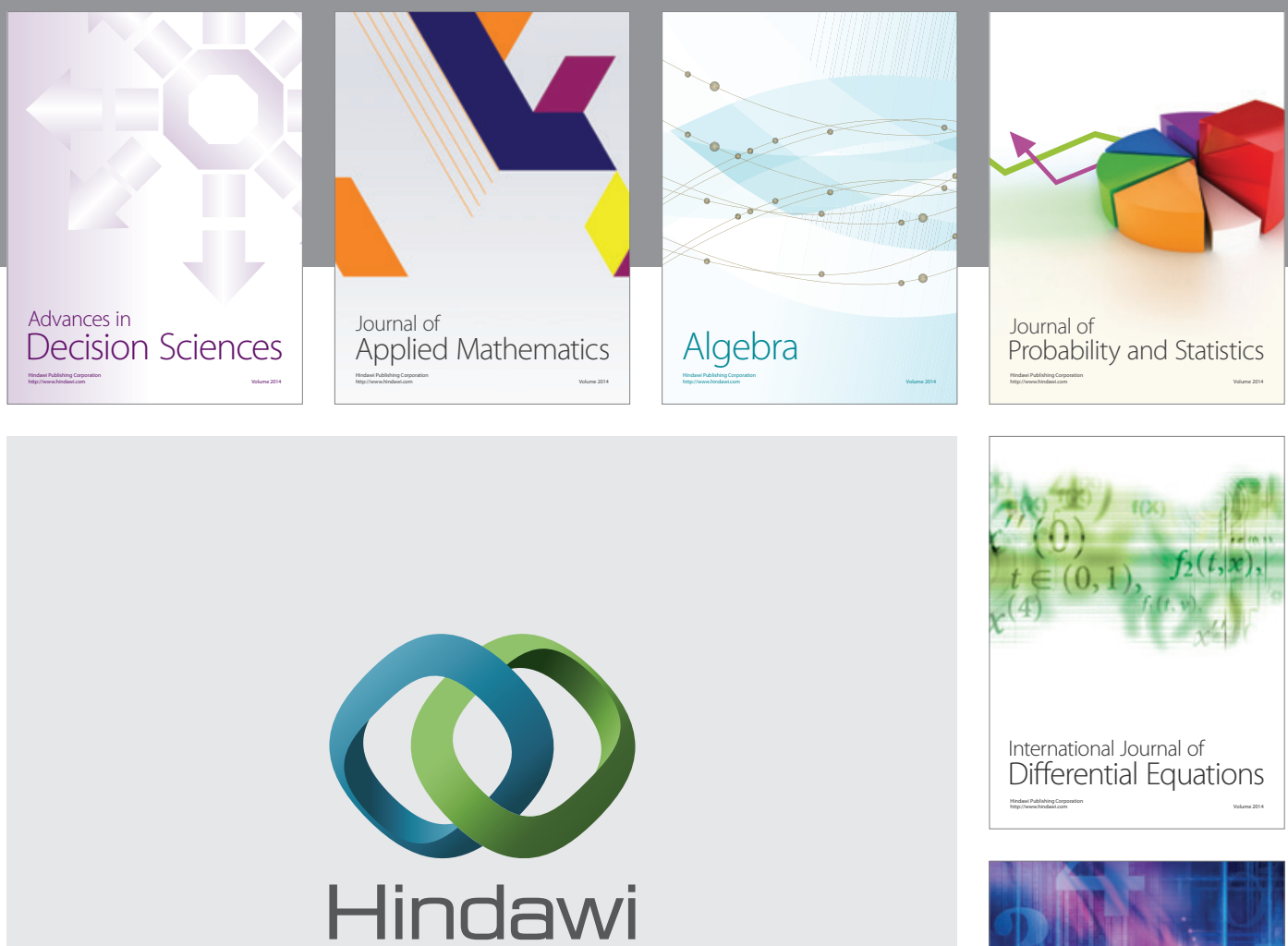

Submit your manuscripts at http://www.hindawi.com
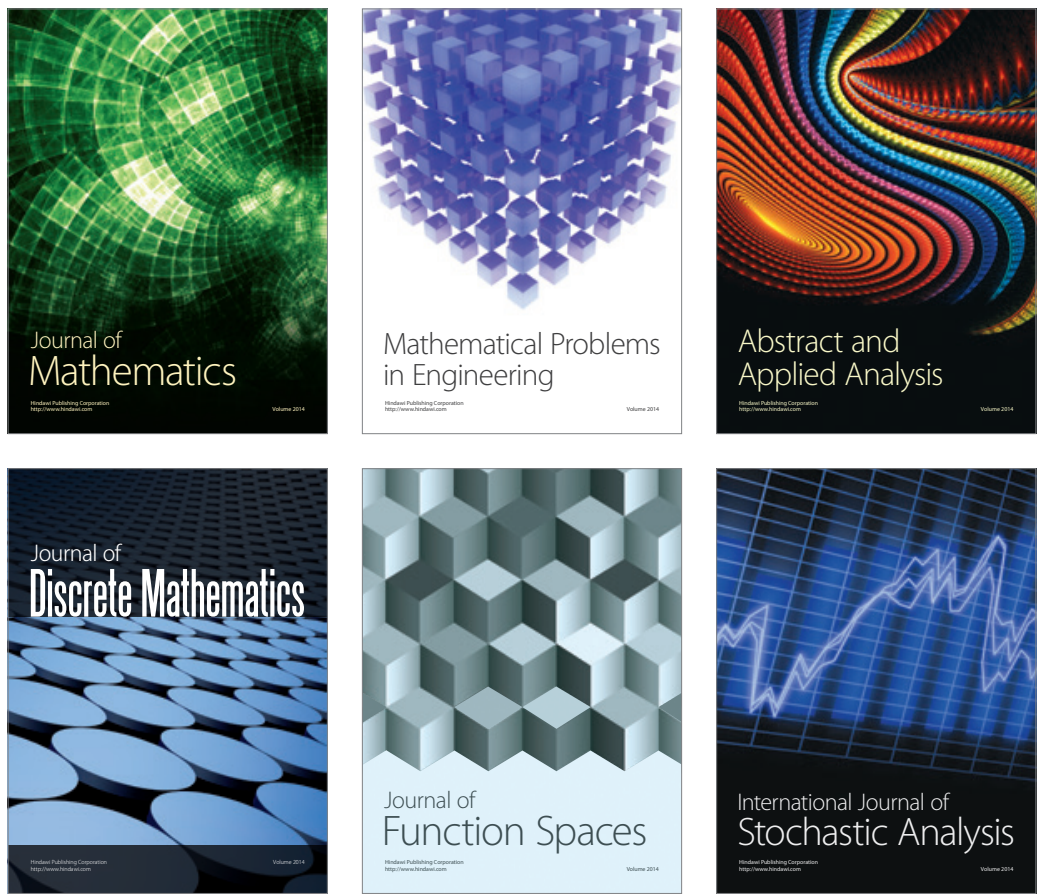

Journal of

Function Spaces

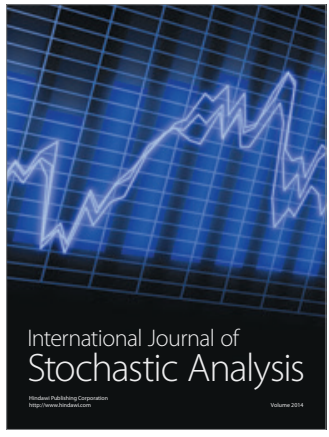

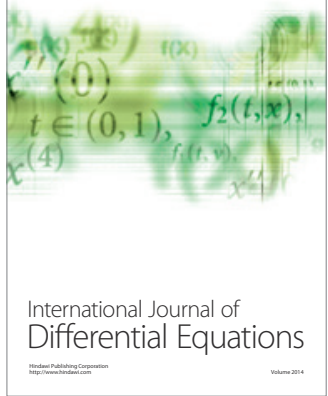
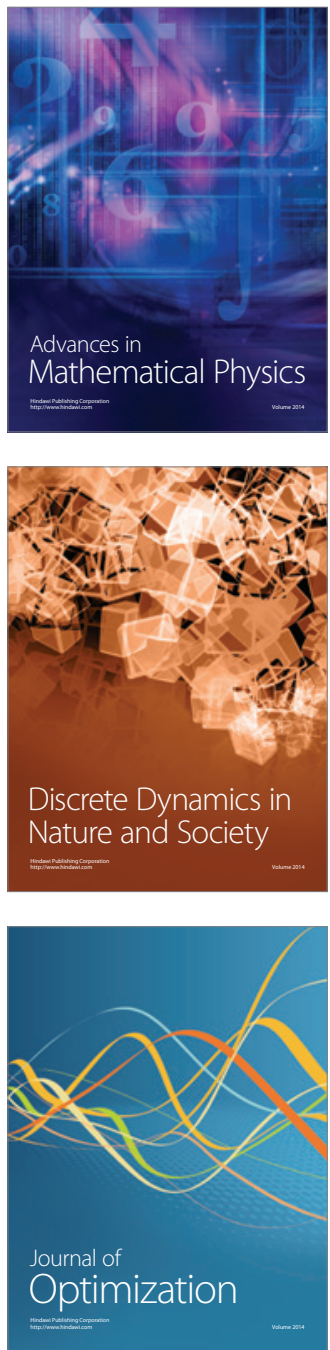